\title{
Epidemiology and interactions of Human Immunodeficiency Virus - 1 and Schistosoma mansoni in sub-Saharan Africa
}

Humphrey D Mazigo ${ }^{1,2,3,4^{*}}$, Fred Nuwaha ${ }^{2}$, Shona Wilson ${ }^{4}$, Safari M Kinung'hi ${ }^{3}$, Domenica Morona', Rebecca Waihenya ${ }^{5}$, Jorg Heukelbach ${ }^{6}$ and David W Dunne ${ }^{4}$

\begin{abstract}
Human Immunodeficiency Virus-1/AIDS and Schistosoma mansoni are widespread in sub-Saharan Africa and co-infection occurs commonly. Since the early 1990s, it has been suggested that the two infections may interact and potentiate the effects of each other within co-infected human hosts. Indeed, S. mansoni infection has been suggested to be a risk factor for HIV transmission and progression in Africa. If so, it would follow that mass deworming could have beneficial effects on HIV-1 transmission dynamics. The epidemiology of HIV in African countries is changing, shifting from urban to rural areas where the prevalence of Schistosoma mansoni is high and public health services are deficient. On the other side, the consequent pathogenesis of HIV-1/S. mansoni co-infection remains unknown. Here we give an account of the epidemiology of HIV-1 and S. mansoni, discuss co-infection and possible biological causal relationships between the two infections, and the potential impact of praziquantel treatment on HIV-1 viral loads, $\mathrm{CD}^{+}$counts and $\mathrm{CD}^{+} / \mathrm{CD}^{+}$ratio. Our review of the available literature indicates that there is evidence to support the hypothesis that $S$. mansoni infections can influence the replication of the HIV-1, cell-to-cell transmission, as well as increase HIV progression as measured by reduced CD4 $4^{+} \mathrm{T}$ lymphocytes counts. If so, then deworming of HIV positive individuals living in endemic areas may impact on HIV-1 viral loads and $\mathrm{CD}^{+} \mathrm{T}$ lymphocyte counts.
\end{abstract}

Keywords: Schistosoma mansoni, HIV-1, Co-infections, Immunological interactions, Deworming

\section{Multilingual abstracts}

Please see Additional file 1 for translations of the abstract into the six official working languages of the United Nations.

\section{Review}

Introduction

Worldwide, HIV-1 infections remain a major public health problem. In 2010, over 31 million adult individuals ( $>15$ years) were living with the disease and new cases of the disease were estimated to be at 2.7 million

\footnotetext{
* Correspondence: humphreymazigo@gmail.com

'Department of Medical Parasitology and Entomology, School of Medicine, Catholic University of Health and Allied Sciences, P.O. Box 1464, Mwanza, Tanzania

${ }^{2}$ Department of Environmental Health and Communicable Disease Control, School of Public Health, College of Health Sciences, Makerere University, P.O. Box 7072, Kampala, Uganda

Full list of author information is available at the end of the article
}

individuals [1]. The sub-Saharan African region continues to carry the largest proportion of the global disease burden [1]. In 2010, over $68 \%$ of global cases of HIV were in sub-Saharan Africa [1]. In this region, an estimated 1.9 million individuals were newly infected with HIV during 2010, comprising about $70 \%$ of all new cases of the disease worldwide [1]. However, in the East African region, the HIV epidemic has started to decline and has stabilized in some areas [2]. The national prevalence of HIV varies among countries in the region, from $3 \%$ in Rwanda, $5.8 \%$ in Tanzania, $6 \%$ in Kenya to $6-7 \%$ in Uganda [2,3]. The risk factors for HIV transmission in sub-Saharan Africa vary dramatically across subpopulations with different demographic characteristics $[4,5]$. The key risk factors for heterosexual transmission of HIV in Africa are commercial sex (prostitution), high population mobility, concurrent or multiple partners or number of lifetime sexual partners, residential location

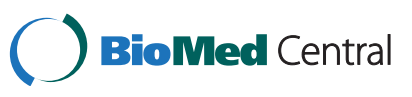


(rural versus urban), history of active or passive sexuallytransmitted disease and lack of male circumcision $[4,5]$. Several epidemiological studies have reported vulnerable groups such as female bar workers [6], female commercial sex workers, long-distance truck drivers and their partners [7]. Fishing communities remain at higher risk of acquiring and transmitting HIV, and play a key role in the spread of HIV and in the maintenance of the HIV infection levels in the population $[8,9]$.

Schistosomiasis is a chronic, water-borne helminth disease, endemic in Africa for many centuries [10-12]. The current global estimate indicates that 779 million people in 76 countries are at risk for schistosomiasis and that 207 millions are infected [13]. Approximately 120 million people have schistosomiasis-related symptoms and 20 million suffer from the chronic form of the disease [14]. In Africa, urogenital schistosomiasis, caused by infection with Schistosoma haematobium, and intestinal schistosomiasis caused by $S$. intercalatum and $S$. mansoni, are highly endemic [13]. However, S. haematobium and S. mansoni are the most widely distributed causing the greatest burden of mortality. A recent metaanalysis of existing data suggests that up to 280,000 deaths annually are related to schistosomiasis (both urogenital and intestinal) in sub-Saharan Africa $[15,16]$. The disability-adjusted life years (DALYs) lost due to schistosomiasis are estimated at 4.5 million [16]. However, not all authors agree with this estimate, some arguing that it is an underestimation of the real impact of schistosomiasis $[15,17]$. There is a real risk that, despite effort to control schistosomiasis, the global prevalence of schistosomiasis may still increase due to the effects of increasing numbers of agricultural irrigation schemes, constructions of dams and man-made lakes for hydroelectric power generation, as well as civil wars, which contribute to increased human population movements $[13,18]$.

In established endemic areas, $S$. mansoni affects individuals of all age groups, but the prevalence and infection intensity is usually seen to peak among children under 15 years of age $[19,20]$. This age-pattern of infection intensity has been reported to develop within 2 years amongst immigrants newly exposed to infection on migration into S. mansoni endemic areas [21]. Although age-specific behavioral patterns, with high water contact and exposure to infection, often favour greater childhood infection intensities, the slow development of a partial immunity in endemic area residents may contribute to the lower infection intensities observed in adults $[22,23]$. However, high occupational exposure, associated with fishing for example, can result in maintenance of high intensities of infection into adulthood [24].

Human Immunodeficiency Virus- 1 and $S$. mansoni infections are co-endemic in Sub-Saharan Africa and coinfection occurs in highly endemic areas (Figure 1)
$[25,26]$. In the early 1990 s, it was hypothesized that helminth infections in sub-Saharan Africa were associated with a high transmission of HIV $[25,26]$ and a faster progression of HIV to AIDS [27-42]. In HIV co-infected individuals, helminth infections may cause general immune activation and affect the pattern of cytokine secretions [25-42]. Further effects observed in HIV-1 - helminth coinfected individuals included the modulation of the immune response against helminths $[28,29,43]$, an impaired schistosome egg excretion [27,31] and increased HIV-1 viral loads after chemotherapeutic deworming [32-42]. The immunological effects and morbidities associated with helminth infections observed in HIV-1 positives individuals vary with the species of helminth involved. Some effects are common to all helminths, others are specific to particular helminth species such as schistosomes. Of the schistosomes that infect man in sub-Saharan Africa, $S$. haematobium, causing urogenital schistosomiasis, presents a distinct and potentially important specific risk factor for the acquisition of HIV-1/AIDS via urogenital tract lesions, and this has been reviewed elsewhere [44-46]. In contrast, S. mansoni, which is the focus of this review, rarely causes genital lesions but may still act as a risk factor for HIV-1 transmission and progression of the disease through within-host interactions with HIV-1. Thus, here we review the evidence for biological causal effects of HIV-1/AIDS and S. mansoni in human hosts. Specifically, we focus on immunological interactions (bi-directional effects in causing morbidities), the efficacy of antischistosome chemotherapy, and its effect on HIV-1 related parameters (such as HIV-1 viral loads and CD4 $4^{+}$lymphocytes) in HIV-1-S. mansoni co-infected individuals.

\section{Methodology}

Data for this review were collected by searches in NCBI PubMed, EMBASE, Global Health and from the references of published manuscripts, relevant articles and doctoral theses. For computerized databases, the search strategy included only permutations of key terms, which were relevant to the study. Initially, all searches began with the text string "schistosom" ${ }^{*}$ " and specified keywords in permutations related to co-infection, including "HIV", "HIV/AIDS", "Viral loads", "co-infection", "deworming", "treatment", "intestinal schistosomiasis", "Schistosoma mansoni", "Schistosoma haematobium", "urinary schistosomiasis", "soil-transmitted helminths" and "filarial". In addition, we reviewed the past and current available publications on WHO, UNAIDS and UNICEF websites, which were relevant to our review.

\section{Characteristics of the immune response to helminth infections}

Most of the human parasitic nematodes and trematodes that occur in sub-Saharan Africa have complex multi- 


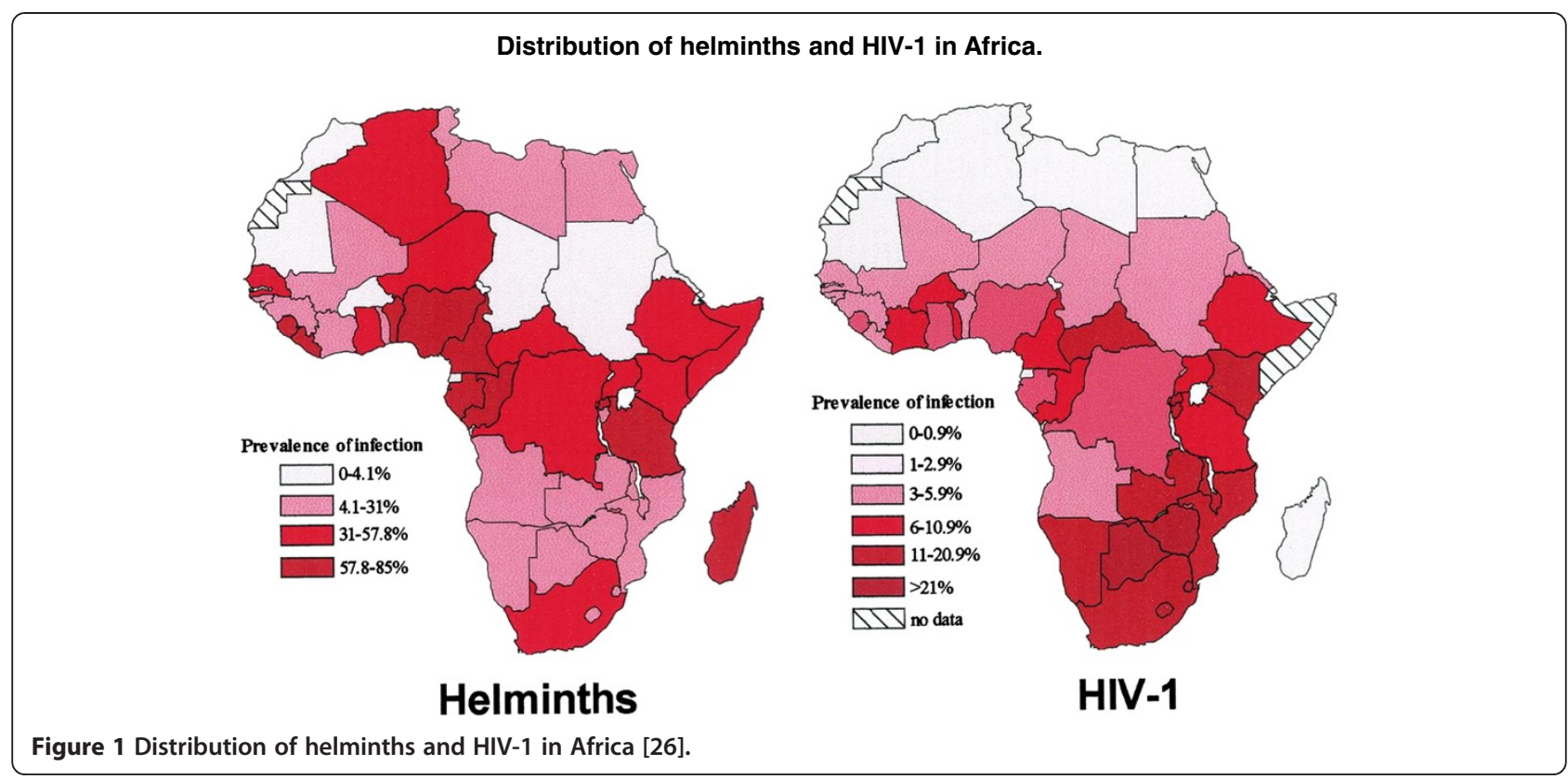

stage lifecycles involving one or two host species and a complex immune modulation response in their hosts [46-50]. The available evidence indicates that the immune responses of various hosts (both natural infections and experimental models) to helminth infection are similar, being commonly characterized by type 2 Thelper lymphocytes with production of significant quantities of interleukin-4, IL-5, IL-9, IL-10 and IL-13 [46-50]. The increased level of $\mathrm{Th}_{2}$ interleukins are accompanied by an increased production of immunoglobulin E (IgE), eosinophils and mast cells responses $[47,48]$. In early helminth infections, the infectious larval stages induce the production of either $\mathrm{Th}_{1}$ or $\mathrm{Th}_{2}$ cytokines response from T-lymphocytes and other immune cells [49]. In S. mansoni infections, the cercaria infective stage stimulates $\mathrm{Th}_{1}$ immune responses during the early phase of the infection in mouse models. In chronic human and experimental infections, Schistosoma mansoni, like all helminth infections, induces a predominantly $\mathrm{Th}_{2}$ immune response, characterized by interleukin-4, IL-5, IL-9, IL-10 and IL-13, antibody (IgE and IgG4), eosinophils and mast cells. However, these responses are tightly regulated to produce a modified $\mathrm{Th}_{2}$ immune environment. The downregulatory mechanisms involved not only down-regulate $\mathrm{Th}_{2}$, but also the $\mathrm{Th}_{1}$ mediated responses that have been observed, in both mice [47,48] and humans [49,50] when exposed to heavy, primary, schistosome infections.

Immunological interactions of Human Immunodeficiency1 and Schistosoma mansoni

\section{Potential immunological interactions}

The major hallmark of HIV-1 infections includes the destruction or depletion of the total body of helper $\mathrm{CD}_{4}^{+}$
T-lymphocytes, both naïve $\left(\mathrm{CD} 45 \mathrm{RA}^{+}\right)$and memory cells $\left(\mathrm{CD}_{4} \mathrm{RO}^{+}\right)$, and a subsequent loss of immune competence $[26,51]$. Studies have indicated that destruction of the $\mathrm{CD}^{+}$cell pool increases susceptibility of the host to other infectious diseases [26]. Earlier studies demonstrated a correlation of maintaining the Th1 $\left(\mathrm{CD}^{+}{ }^{+}\right.$ T-lymphocytes) immune profile and slow progression of the HIV-1 infections [52-56]. During this phase, uncontrolled replication of the HIV-1 infections leads to activations of the $\mathrm{CD}^{+}$T-lymphocytes (those expressing CD38, CD45RO and HLA-DR) [57-60] and increased concentration of cytokines such as IFN- $\alpha, \mathrm{TNF}-\gamma$ and IL-1 $\beta$ [52,57-60]. A switch of the immune response from Th1 (CD8 ${ }^{+}$T-lymphocytes) to Th2 (CD4 ${ }^{+}$T-lymphocytes) with subsequent production of its associated cytokines are related to fast progression of the disease and chronic activation of the immune responses [52,55]. The proliferations of the Th2-CD4 $4^{+}$is also associated with the proliferations of other related $\mathrm{CD}_{4}^{+}$regulatory subsets such as $\mathrm{CD} 4^{+}$ $\mathrm{CD}_{25}{ }^{+}\left(\mathrm{CD}^{+} \mathrm{T}_{\text {reg }}\right)$ which have been shown to express Cytotoxic $\mathrm{T}$ lymphocyte-associated antigen 4 (CTLA-4) that exerts an inhibitory effect on $\mathrm{T}$ cell proliferation by secreting immunosuppressive cytokines such as TGF- $\beta$ and IL-10 [60-65]. The TFG- $\beta$ plays a pivotal role in $\mathrm{CD}^{+}$ $\mathrm{T}$-cell regulation by inhibiting its proliferation and acquisition of the effectors function by the naïve T-cells [66]. Increased CTLA- 4 expression correlates with markers of HIV disease progression and the up-regulation of the CTLA- 4 also increases CCR5 expression on the surfaces of $\mathrm{CD}^{+}$T-lymphocytes which enhance the susceptibility of these cells to HIV-1 infections and cell to cell HIV transmission [67]. Studies have indicated that destruction of the $\mathrm{CD}^{+}$cell pool by HIV-1 infection increases 
susceptibility of the host to other infectious diseases [26]. These immune characteristics of HIV-1 and S. mansoni infections clearly give rise to the potential for a number of immunological one-way and two-way modulating interactions between them in co-infected populations.

The $\mathrm{CD}^{+}{ }^{+} \mathrm{T}$-helper lymphocytes responses are central to the development of immunopathology in $S$. mansoni infections [68]. The chronic phase, which is characterized by the production of soluble egg antigens (SEA), the inflammatory cytokines response to SEA are significantly reduced and the Th2 response is characterized by up-regulation of IL-10 and TGF- $\beta$ which down-regulates the production and effectors functions of the Th1 response $[69,70]$. The release of these cytokines leads to the productions of the IgG4, suppressed parasitesspecific $\mathrm{T}$ cell proliferation, reduced level of Th2 and Th1 cytokines [71]. At this stage only few S. mansoni infected individuals develop severe hepatosplenic disease characterized with development of granulomas [71-74]. The resulting $\mathrm{T}$ - dependent granulomas protect host tissues from egg-produced antigens [75]. The granulomas around the trapped eggs are composed of collagen fibers and inflammatory cells of $\mathrm{Th}_{2}$ origins, including eosinophils, macrophages and $\mathrm{CD} 4^{+}$T-cells [74]. In addition, the mechanisms responsible for granuloma formation are also involved in the process of S. mansoni eggs excretion [76]. In fact, individuals with chronic S. mansoni pathologies express high level of Th1 and Th17 responses which lead to inflammation and fibrosis around the deposited schistosomes eggs in tissues [71].

\section{Effects of HIV-1 on Schistosoma mansoni}

The destruction of helper $\mathrm{CD}_{4}^{+}$T-lymphocytes by the HIV-1 virus in co-infected individuals could affect granuloma formation, and alter egg excretion efficiency. Studies on immuno-suppression animal models have demonstrated that the excretion of S. mansoni eggs is immune dependent, and that T-cells, specifically the anti-egg $\mathrm{Th}_{2}$ responses [77] are necessary for the transposition and excretion of eggs from the host blood stream into the intestinal lumen $[78,79]$ as well as the development of granuloma [80,81]. In Kenya, Karanja et al. [82] demonstrated that HIV infected individuals had a reduced eggs excretion of $S$. mansoni, correlated with decreased $\mathrm{CD} 4^{+} \mathrm{T}$ lymphocytes counts [82]. Similar observations on the reduced eggs excretion were reported in HIV-1 positive individuals co-infected with S. mansoni and S. haematobium in Ethiopia, Zambia and Congo [25,82,83]. In rural Zimbabwe, although the study was limited by low infection intensities of $S$. mansoni, no association was demonstrated between the HIV-1 status or CD4 ${ }^{+} \mathrm{T}$ lymphocytes counts and the eggs excretion efficiency [27]. Based on these observations on the $\mathrm{CD}^{+}$T-lymphocytes response during $S$. mansoni infection in multiple animal models and human studies, could lead to greater numbers of eggs retained in the host's affected body organs. If this hypothesis is correct, then HIV-1 positive individuals co-infected with $S$. mansoni might have altered morbidity (i.e. less fibrous material formation at the granuloma area, or inability to contain the egg released antigens) than individuals infected with $S$. mansoni alone. This could have a significant bearing on the parasitological diagnosis of the infection, which is dependent on detection of excreted parasite eggs [30].

The potential for HIV to affect $S$. mansoni egg excretion not only potentially affects parasitic diagnosis of infection, but also co-infection studies, this makes the detection of circulating schistosome antigens released by in situ worms particularly important in detecting and, to some extent quantifying, these infections. Circulating Cathodic Antigens (CCA) and Circulating Anodic Antigen (CAA) are S. mansoni related gut antigens which are regurgitated by the adult and juveniles stages with the by-products of host red blood cell digestion. CCA can now be detected by antibody-based rapid diagnostic tests in urine samples [42,84]. Such antigen-detection tests have many advantages, including demonstration of active infections of $S$. mansoni in the absence of detectable egg excretion, the effects of treatment and in term of diagnosis it has high specificity [42,84]. When CAA/ CCA positivity has been employed as a diagnostic criterion for S. mansoni infection after praziquantel treatment in HIV-1 and S. mansoni co-infected individuals compared with those with only $S$. mansoni infections. The result showed a lower clearance rate of the adult worms in treated HIV-1 positive individuals co-infected with $S$. mansoni [41]. This observation was inconsistent with the results of Karanja et al. [40], who identified equally decreased levels of CCA following praziquantel therapy in individuals who were HIV-1 positive and co-infected with $S$. mansoni as compared to individuals with $S$. mansoni infection only [41]. It was argued that the difference in S. mansoni intensity of infection between the two study populations and the dominance of $S$. haematobium in the study of Kallestrup et al. [41] could have contributed to the discordance between those studies' results. The discrepancy observed between these studies calls for further studies to elucidate efficacy of praziquantel in HIV-1 infected individuals co-infected with $S$. mansoni.

Granuloma formation in S. mansoni infection is a $\mathrm{CD}^{+}$dependent process and earlier studies have hypothesized that the destruction of helper $\mathrm{CD} 4^{+}$T-lymphocytes $\left(\mathrm{Th}_{2}\right)$ by HIV-1, coupled with the significant importance of $\mathrm{CD}^{+}$cells in the formation of granuloma, may lead to a decreased ability of the $\mathrm{Th}_{2}$ arm to produce proinflammatory cytokines such as TNF- $\alpha$, IL-6, IL-1, IL-13 
which are responsible for stimulating the inflammatory cells responsible for fibrogenesis, and hence lead to severe hepatic morbidity [78,85]. Immunological studies have demonstrated that, T-cells from the peripheral blood of HIV-1 positive individuals co-infected with $S$. mansoni responded to egg antigens by producing less IL-4 and IL-10 and a lower amount of IFN- $\gamma$ as compared to those from individuals infected with S. mansoni alone, indicating immune skewing from $\mathrm{Th}_{2}$ to $\mathrm{Th}_{1}$ [78]. Supportive evidence from animal models indicates that, granuloma formation is severely restricted in immunodeficiency mouse models $[80,81]$. It is possible that granuloma formation may help to contain hepatotoxins (omega-1-ribonuclease and IPSE/alpha-1) that are released from S. mansoni eggs trapped in the liver [86-88] which may increase the risk of liver parenchyma damage and cause severe necrosis $[75,76,89]$.

A community-based study in fishing communities in northwest Tanzania, showed that there were no differences in the distribution of $S$. mansoni related morbidities, as detected by ultrasonography, between HIV co-infected individuals with $S$. mansoni and those with single infection of S. mansoni [79]. This study though did not measure the $\mathrm{CD}^{+}$counts of the $\mathrm{HIV}-1^{+}$positive study participants coinfected with S. mansoni. Similarly, in Kenya, there were no significant differences in the distribution of ultrasounddetectable pathology (hepatomegaly, splenomegaly, hepatic fibrosis, periportal fibrosis and gallbladder wall thickness) in HIV-1 positive individuals co-infected with $S$. mansoni as compared with HIV-1 negative individuals infected with S. mansoni [43]. The study demonstrated that hepatic fibrosis, in the absence of severe hepatosplenomegaly, was associated with a significant decrease in $\mathrm{CD}_{4}^{+}$T-lymphocytes in HIV-1 negative individuals infected with $S$. mansoni, and that the decrease correlated with increasing grade of liver fibrosis [43]. In HIV-1 positive individuals co-infected with S. mansoni, reduced CD4 ${ }^{+}$T-cells counts levels did not necessarily imply the development of severe hepatic morbidities or altered patterns of hepatic fibrosis due to the effects of hepatotoxins [43]. In addition, there was no difference in the level of measurable fibrosis and the level of liver parenchyma damage as measured by the levels of circulating liver enzymes (glutamic oxaloacetic transaminase and aspartate aminotransferase) in individuals with HIV-1 co-infection as compared with HIV-1 negative individuals infected with $S$. mansoni [43]. Importantly, there were no significant correlations between $\mathrm{CD} 4^{+} \mathrm{T}$ cells count and circulating liver enzyme levels in HIV-1 positive individuals co-infected with $S$. mansoni or in HIV-1 negative individuals infected with S. mansoni [43]. However, it is worth noting that the passive transfer of specific anti-omega 1 antibody is sufficient to completely prevent hepatocyte damage in S. mansoni infected immunosuppressed mice that have severely impaired anti-egg granuloma [90]. Anti-omega 1 antibodies were not assayed in the human studies [43]. The observation that hepatic fibrosis is associated with reduced $\mathrm{CD} 4^{+}$T-lymphocytes in HIV-1 positive and negative individuals implies that $S$. mansoni associated liver pathologies could speed up the progression of HIV to AIDS through the depletion of $\mathrm{CD}^{+}{ }^{+} \mathrm{T}$ cells in co-infected individuals [43]. It could also be speculated that, the hyporesponsiveness of the T-cells due to chronic activations of the immune system and differentiations of the $T_{\text {regs }}$ and released of TGF- $\beta$ and IL-10 could in part explains the low $\mathrm{CD} 4^{+}$counts observed in HIV-1 positive and HIV-1 negative individuals infected with S. mansoni. However, this observation calls for further studies to confirm the observation.

\section{Effects of Schistosoma mansoni on HIV-1}

Schistosoma mansoni infections induce an immune modulation, which shifts from T-helper 1 to predominant T-helper 2 cytokines $[69,70,91]$. The cytokines associated with T-helper 2 lymphocytes down-regulate the cytotoxic effects of T-cytotoxic $\left(\mathrm{CD}^{+}\right)$lymphocytes which are essential for the initial control of viral replication $[69,70,81,91]$. In animal studies, mice co-infected with $S$. mansoni and vaccinia virus expressing the HIV envelope displayed a shift towards a $\mathrm{Th}_{2}$ response which down-regulated $T h_{1}$ cytokines production and impaired the cytotoxic effects of $\mathrm{CD}^{+}$on the virus $[81,82]$. In addition, an increase in viral replication and the alteration of T-cells subsets have been observed in Rhesus Macaque monkeys co-infected with S. mansoni [92]. In human studies, HIV-1 positive individuals co-infected with $S$. mansoni in western Kenya demonstrated an alteration of the immune response to $S$. mansoni characterized by a low level of IL-4 and IL-10 production [78].

In vitro studies on human peripheral blood mononuclear cells from individuals infected with schistosomiasis have shown an increased susceptibility of these cells to HIV-1 as compared to helminth free individuals [31]. The expression of the chemokine receptors CCR5 and CXCR4 on the surfaces of CD4+ $4^{+}$-lymphocytes, which have been stimulated by $\mathrm{Th}_{2}$ cytokines, make these cells more susceptible to HIV-1 infection [31,32]. In fact, these receptors serve as co-receptors for HIV-1 entry into the cells $[31,32]$. In Kenya, individuals infected with schistosomiasis expressed higher cell surface densities of these receptors as compared to individuals cured of the disease [31]. These observations imply that HIV-1 replication proceeds more rapidly in activated $\mathrm{T}$ cells, especially in those with $\mathrm{Th}_{2}$ or $\mathrm{Th}_{0}$ phenotypes [32].

Individuals co-infected with HIV-1 and S. mansoni may have reduced ability to mount potent protective immune responses against a number of viral infections. Similarly, individuals co-infected with chronic Hepatitis C virus 
(HCV) and S. mansoni demonstrated a decreased HCVspecific $\mathrm{CD}^{+} \mathrm{T}$ cell proliferative response as compared with individuals with $\mathrm{HCV}$ alone [33]. In Uganda, concomitant infections of $S$. mansoni and $\mathrm{HIV}-1$ was associated with decreased Gag-specific cytolytic $\left(\mathrm{CD}^{+}\right)$ responses, showing an alteration of the effectors functions of HIV infection attributed to schistosomiasis [34]. Moreover, the detection of Gag-specific positive $\mathrm{CD}^{+} \mathrm{T}$ cells in co-infected individuals shows that $S$. mansoni may be responsible for the modulation of the cellular immune response to HIV [34]. T-regulatory cells are an important component of regulation of $\mathrm{T}$ cell activation. It has been reported that an expansion in $\mathrm{T}$ regulatory cells ( $\mathrm{T}$-reg) occurs during the chronic phase of HIV infection. There is some debate as to whether the expansion of T-reg numbers is detrimental, due to suppression of cellular mediated immunity, or beneficial, due to limiting cellular activation, and therefore co-receptor expression and targets for HIV-1 infection [93]. Schistosoma mansoni infection was found to expand the proportion of circulating CD25hi CD4 ${ }^{+}$cells, a significant proportion of which are likely to be FoxP3 ${ }^{+}$ve T-reg cells, amongst sand-harvesters in Kisumu, Kenya [94]. However, no significant difference in the proportion of $\mathrm{CD} 4{ }^{+} \mathrm{CD} 25 \mathrm{hi}$ cells was observed between individuals who were sero-positive and negative for HIV-1 [94]. As the role of T-regs in HIV infection is clarified [52,53], further studies using a wider range of T-reg markers such as FoxP3 ${ }^{+}$ve and CD127lo $[95,96]$ will be required to determine whether this important sub-type is affected by co-infection with $S$. mansoni.

Evidence suggests that the expression of the coreceptors on activated $\mathrm{CD}^{+} \mathrm{T}$ lymphocytes increases the susceptibility of these cells to HIV infection in HIVuninfected populations, and may also speed up the progression of HIV to AIDS by increasing plasma viral loads and decreasing $\mathrm{CD}^{+}{ }^{+}$T-lymphocytes in coinfected individuals [31,32]. Increased HIV plasma viral loads determine disease progression and risk for HIV transmission in between partners [35]. However, most cross-sectional and other observational studies have failed to provide evidence that decreased $\mathrm{CD}^{+}{ }^{+} \mathrm{T}$ cells and increased HIV-1 viral loads is associated with heavy helminth infections [29,36,37]. Previous authors have suggested that helminth infection intensity could in part contribute to decreased $\mathrm{CD} 4^{+} \mathrm{T}$ cell counts or speed up the progression of HIV-1 to AIDS, meaning that HIV-1 positive individuals with higher $S$. mansoni infection intensity could have reduced $\mathrm{CD}^{+} \mathrm{T}$ cells counts and higher HIV-1 viral loads. Similar findings on the other helminth species have been reported [83]. There is however no evidence on the linear relationship between $S$. mansoni infection intensity and HIV-1 viral loads in coinfected individuals and this calls for further studies.

\section{Efficacy of praziquantel treatment of Schistosoma mansoni in HIV-1 co-infected individuals}

In the last three decades, praziquantel has been the drug of choice for treatment of schistosomiasis, especially in sub-Saharan Africa, because of its high level of efficacy against all schistosome species, its ease of administration and lack of serious adverse effects [97]. A single dose of $40 \mathrm{mg} / \mathrm{kg}$ body weight is reported to result into human schistosomiasis cure rates that vary widely $(60 \%-90 \%)$ between different studies, but which consistently result in reductions of infection intensity of more than 95\% $[23,98]$. The efficacy of praziquantel depends to some extend on its synergy with an intact immune response, studies in immunodeficient animal models have demonstrated reduced efficacy of praziquantel [98-101]. In addition, praziquantel efficacy can be increased by preimmunization of mice with schistosome antigens, whereby the generated parasite-specific antibodies increase praziquantel efficacy [78,79]. Several studies have been carried out in HIV-1 positive individuals to test whether or not the efficacy of praziquantel has an immune dependent component in human-S. mansoni infections, as this has been reported in mice [40-42].

In western Kenya, a study was carried out involving male car-washers ( $>18$ years) in which 15 individuals were co-infected with S. mansoni and HIV-1 and 32 individuals had S. mansoni infection alone [40]. Majority of these individuals had heavy infections of $S$. mansoni. The results of that study indicated that HIV-1 sero-positivity status did not affect the efficacy of praziquantel. In the treated groups (HIV-1 positive co-infected with $S$. mansoni versus HIV-1 negative infected with S. mansoni), a single dose of praziquantel resulted in a $>93 \%$ reduction in $S$. mansoni infection intensity regardless of HIV-1 serostatus and percentage of $\mathrm{CD}^{+}{ }^{+} \mathrm{T}$ - cell [40]. Similarly, a prospective cohort study in Zambia which included individuals aged 10 - 55 years, in which 47 were co-infected with HIV-1 and S. haematobium and 335 HIV-1 negative individuals infected with $S$. haematobium demonstrated that praziquantel treatment resulted in $99.81 \%$ reduction in average infection intensity, despite a concurrent HIV-1 infection [42].

\section{Effects of praziquantel treatment of S. mansoni on HIV-1 viral loads and $\mathrm{CD}^{+}$T-lymphocytes levels in co-infected individuals}

The individual immunological interactions between these two common pathogens suggest that increased expression of $\mathrm{Th}_{2}$ cytokines caused by $S$. mansoni, raising the possibly that co-infection may increase HIV replication and cellto-cell transmission, as well as increase the rate of HIV progression, as measured by reduced $\mathrm{CD}^{+} \mathrm{T}$ lymphocyte counts [102]. If so, then deworming of HIV positive individuals living in endemic areas may reduce the HIV-1 viral 
loads and increase both the $\mathrm{CD}^{+} \mathrm{T}$ lymphocyte counts immune responsiveness of the T-cells to both HIV-1 and S. mansoni infections [103-107].

Recent data from randomized control trials and observational studies have highlighted decreased HIV-1 viral loads, decreased expression of co-receptors CCR5 and CXCR4 on the surface of $\mathrm{CD}_{4}{ }^{+} \mathrm{T}$ lymphocytes and improved $\mathrm{CD} 4^{+} \mathrm{T}$ lymphocytes counts, following the treatment of various species of helminths [31,103-106,108-111]. Praziquantel treatment in S. mansoni infected Kenyan car washers resulted in a drop of CCR5 and CXCR4 levels expressed on the CD4 ${ }^{+}$ $\mathrm{T}$ lymphocytes in both HIV-1 infected and un-infected individuals, suggesting that the treatment of individuals infected with $S$. mansoni alone, or co-infected with HIV-1 and $S$. mansoni, could decrease the risk of HIV transmission to individuals with schistosomiasis, or intercellular transmission in HIV-1 infected individuals [31]. In rural Zimbabwe, praziquantel treatment of HIV-1 co-infected individuals resulted in the decline of $\mathrm{HIV}-1$ viral loads in the group that received immediate treatment as compared with those who received treatment three months later [109]. In addition, despite an observed increase in HIV-1 viral loads after three months, the mean HIV-1 viral loads in the early treatment group was lower than in the delayed treatment group [109]. However, subsequent studies did not observe any impact of anthelminthic treatment and decline in HIV-1 viral loads, lower $\mathrm{CD}^{+} \mathrm{T}$ lymphocytes or faster progression to AIDS [37,39,110]. In Uganda, a significant transient increase in HIV-1 viral loads and a decrease in $\mathrm{CD}^{+} \mathrm{T}$ lymphocytes were observed one month postpraziquantel treatment in HIV-1- S. mansoni co-infected individuals [37,111]. The mechanisms that might favour increased viral loads and decreased $\mathrm{CD}^{+}{ }^{+} \mathrm{T}$ lymphocytes remain unclear and open up a number of interpretations. It is possible that the adult worm death following praziquantel treatment provides an antigenic stimulation that increases $\mathrm{Th}_{2}$ activation and hence increases HIV-1 replication $[31,102,112,113]$. Alternatively, anthelminthic treatment may suppress the production of inflammatory and antiinflammatory cytokines that are maintained by chronic helminth infections [113].

Increased levels of $\mathrm{CD}^{+} \mathrm{T}$ lymphocytes in HIV-1 positive individuals co-infected with $S$. mansoni have been reported after praziquantel treatment [109]. In rural Zimbabwe, a randomized control trial reported increased $\mathrm{CD}^{+}$ $\mathrm{T}$ lymphocyte counts in those receiving praziquantel treatments, as compared to those treated three months later [108]. However, this observation contrasted with other similar studies that reported decreased $\mathrm{CD} 4^{+} \mathrm{T}$ lymphocyte counts after praziquantel treatment $[36,37,39,110]$. The lack of consistency between these studies calls for further studies to clear the observed discrepancies.

\section{Effects of praziquantel treatment on hepatic morbidities in co-infected individuals}

The intestinal form of schistosomiasis mansoni is characterized by abdominal pain, diarrhea, bloody stool, nausea, fatigue and drowsiness. S. mansoni eggs that do not penetrate the gut wall can pass via the portal vein to be trapped in the liver tissues where they provoke vascular, inflammatory and granulomatous changes [114]. In severe advanced cases, this can lead to hepatosplenomegaly and portal hypertension, which can lead to development of oesophageal varices, ascites and risk of haematemesis [114]. Autopsy studies have associated severe hepatosplenic disease and portal hypertension with gross hepatic periportal fibrosis $[115,116]$.

The impact of praziquantel treatment on $S$. mansoni is not only evaluated in terms of reduction in the infection intensity but also in terms of the reversibility of hepatosplenic morbidities after treatment [97,117-121]. Not all $S$. mansoni associated hepatosplenic morbidities reverse after treatment, mild or low grade periportal fibrosis can be seen to reverse 12 months after treatment, but advanced periportal fibrosis is considered to be irreversible and studies have reported the progression of organomegaly (hepatomegaly or splenomegaly to hepatosplenomegaly) after treatment $[121,122]$.

Based on the reduced anti-egg granulomatous response and fibrosis $[75,76,89]$ and the reduced efficacy of praziquantel treatment, reported in immunosuppressed mice [98-101], it is possible that human HIV-1 infection could impact on co-infecting schistosome morbidity, including regression or progression of hepatic morbidity after praziquantel treatment. As yet, only one human ultrasound study of HIV-1 and S. mansoni co-infection hepatic morbidity has been reported [43]. To date, no single study has evaluated the impact of praziquantel treatment on hepatic and splenic morbidities in individuals co-infected with $S$. mansoni and HIV-1. This calls for further studies on large sample sizes to understand the liver and spleen morbidities in individuals co-infected with HIV-1 and S. mansoni.

\section{Possible implications of HIV-1 and S. mansoni co-infection on Mass Drug Administration}

Based on the evidence above on the interactions between HIV-1 and S. mansoni in sub-Saharan Africa and the fact that the two infections are highly prevalent, coinfections with the two diseases in high risk groups such as fishing communities are possibly high and their interactions could be the cause of the severe morbidities observed and high prevalence of HIV-1. Despite the potential risks related to co-infection, little is known of the interaction between these infections in high-risk communities [70]. In the sub-Saharan Africa, the control of schistosomiasis focuses mainly on the reduction of morbidities and mainly targets groups at risk [97]. Control 
approaches often involve Mass Drug Administration (MDA) of praziquantel to treat schistosomiasis, combined with albendazole to treat nematode infections, to schoolchildren or through child health clinics [97]. Occasionally, MDA is preceded by mass screening of schistosomiasis before treatment for the purpose of monitoring the impact of MDA on targeted infections [97]. Evidence from clinical studies suggests that deworming of HIV-infected individuals reverses the immune response to normal, leads to a decline in HIV-1 viral loads and the expression on the surface of $\mathrm{CD}^{+} \mathrm{T}$ lymphocytes of co-receptors responsible for cell to cell transmission of HIV-1, and an increase in $\mathrm{CD}^{+} \mathrm{T}$ lymphocyte numbers [103-106,123-127]. Thus, identification of individuals co-infected with HIV-1 and $S$. mansoni at very early stages for early de-worming, even if it only results in small reductions in viral load, may have benefits in delaying the progression or decrease the spread of the disease and importantly, may delay an individual's need to begin anti-retroviral treatment (ARV) [126].

Despite the evidence that praziquantel has effects on some of the HIV-1 outcome parameters, there are still a number of issues that remain unsolved and will require further studies to investigate the exact mechanism of interaction between helminth and HIV-1 infections and the impact of anthelminthic treatment. The majority of the previous studies on this topic, were almost all crosssectional in design, and some had significant limitations, including the interpretation of the results, the lack of comparison groups, short follow-up periods and small population sample sizes [91]. These limitations could in part be the cause of discrepancies between results: while some studies agree with the hypothesis that anthelminthic treatment either with albendazole (for gut nematodes), diethylcarbamazine (for filarial worms) or praziquantel, have positive effects on HIV-1 parameters, other studies do not agree with this observation. As yet, there is insufficient data to show clearly that de-worming of HIV-1 co-infected individuals has a beneficial effect on HIV-1 viral loads and CD4. lymphocytes. As suggested by other authors, longitudinal studies exploring the interactions of HIV-1 and S. mansoni infections are warranted. These studies should focus on understanding the effects of the intensity of $S$. mansoni infection on HVI-1 viral loads and CD4 $4^{+} \mathrm{T}$ lymphocytes and on the development of hepatosplenic pathologies in co-infected individuals. The assessment of the impact of anthelminthic treatment on HIV-1 parameters should be made a priority.

\section{Conclusion}

In Sub-Saharan Africa, HIV-1 and S. mansoni infections are co-endemic and co-infection occurs in highly endemic areas. There is evidence to support the occurrence of interactions between the two infections in a single co-infected human host. Furthermore, published data supports the hypothesis that helminth infections can influence important parameters of HIV infection such as $\mathrm{CD}^{+}$lymphocyte counts and HIV viral loads. Thus, in areas of co-endemicity, it is important to integrate control programmes for HIV-1 and schistosomiasis to give an opportunity for early identification of coinfected individuals and provide an opportunity for early deworming to reduce the fast progression and transmission of HIV-1.

Lastly, the available evidence on the interactions of HIV-1 and S. mansoni and the impact of praziquantel treatment on $\mathrm{CD}^{+}$lymphocytes and HIV-1 viral loads remains inconclusive and does call for further field studies to resolve discrepancies. Large randomized controlled trials with longer follow-up periods are required in order to assess the interactions between S. mansoni and HIV-1 and the impact of deworming cycles on the HIV-1 progression in populations constantly exposed to S. mansoni infection and at high risk of HIV infection.

\section{Additional file}

Additional file 1: Multilingual abstracts in the six official working languages of the United Nations.

\section{Competing interest}

HDM is supported by the Training Health Researchers into Vocational Excellence in East Africa (THRiVE) Programme funded by Wellcome Trust, grant number 087540. The authors declare that there have no competing interest.

\section{Authors' contributions}

HDM designed the study, searched for literature and prepared the first draft of the manuscript, FN, SW, SMK, DM, RW, JH and DWD critically reviewed the manuscript. All authors have read and approved the final manuscript.

\section{Acknowledgements}

None

\section{Author details}

'Department of Medical Parasitology and Entomology, School of Medicine, Catholic University of Health and Allied Sciences, P.O. Box 1464, Mwanza, Tanzania. ${ }^{2}$ Department of Environmental Health and Communicable Disease Control, School of Public Health, College of Health Sciences, Makerere University, P.O. Box 7072, Kampala, Uganda. ${ }^{3}$ National Institute for Medical Research, Mwanza Research Centre, P.O. Box 1462, Mwanza, Tanzania. ${ }^{4}$ Department of Pathology, University of Cambridge, Tennis Court Road, Cambridge CB2 1QP, UK. ${ }^{5}$ Department of Zoology, Faculty of Science, Jomo Kenyatta University of Agriculture and Technology, P.O. Box 62,00000200, Nairobi, Kenya. ${ }^{6}$ Department of Community Health, School of Medicine, Federal University of Ceará, Ceará, Brazil.

Received: 13 November 2012 Accepted: 17 January 2013 Published: 24 January 2013

\section{References}

1. WHO/UNAIDS/UNICEF. Global HIV/AIDS response: Epidemic updates and health sector progress towards universal access, Progress report ; 2011:1-164. 
2. Hallett TB, Stover J, Mishra V, Ghys PD, Gregson S, Boema T: Estimates of HIV incidence from household-based prevalence surveys. AIDS 2010, 2:24,1:147-152.

3. Swai R, Van Asten H: Epidemiology of HIV infection in Tanzania-an update. Tanz Med J 1991, 2:33-39.

4. Quigley M, Munguti K, Grosskurth H, Todd J, Mosha F, Senkoro K, Newell J, Mayaud P, Ka-Gina G, Klokke A, Mabey D, Gavyole A, Hayes R: Sexual behaviour patterns and other risk factors for HIV infection in rural Tanzania: a case-control study. AIDS 1997, 11(2):237-248.

5. Mnyika KS, Klepp KI, Kvale G, Ole-King'ori N: Risk factors for HIV-1 infection among women in the Arusha region of Tanzania. J Acq Immune Deficy Synd Human Retrov 1996, 15;11:5:484-491.

6. Kapiga SH, Sam NE, Shao JF, Renjifo B, Masenga EJ, Kiwelu IE, Manongi R, Fawzi W, Essex M: HIV-1 Epidemic Among Female Bar And Hotel Workers in Northern Tanzania: Risk Factors and Opportunities for Prevention. J Acq Immune Def Synd 2002, 29(4):409-417.

7. Carswell JW, Lloyd G, Howells J: Prevalence of HIV-1 in east African lorry drivers. AIDS 1989, 3:759-761

8. Kissling E, Allison EH, Seeley JA, Russell S, Bachmann M, Musgrave SD, Heck $\mathrm{S}$ : Fisherfolk are among groups most at risk of HIV: cross-country analysis of prevalence and numbers infected. AIDS 2005, 19:1939-1946.

9. Asiki G, Mpendo J, Abaasa A, Agaba C, Nanvubya A, Nielsen L, Seeley J, Kaleebu P, Grosskurth H, Kaali A: HIV and syphilis prevalence and associated risk factors among fishing communities of Lake Victoria, Uganda. Sex Trans Infect 2011, 87(6):511-515.

10. Pfister E: Schistosomiasis (Bilharziasis). Archive Gesch. Med 1912, 6:12-20.

11. Ruffer SMA: The presence of ova in mummies and Canopic jar of mummified viscera. Br Med J 1910, 1:16-25.

12. Eltawil KM, Plassmann M: Theodor Maximillian Bilharz (1825-1862): The discoverer of Schistosomiasis. Intern J Parasitol Res 2011, 3(1):17-25.

13. Steinmann P, Keiser J, Bos R, Tannel M, Utzinger J: Schistosomiasis and water resources development: systematic review, meta-analysis and estimates of people at risk. Lancet 2006, 6:411-425.

14. Chitsulo L, Engels D, Montresor A, Savioli L: The global status of schistosomiasis and its control. Acta Trop 2000, 77:41-51.

15. Van der Werf MJ, de Vlas SJ, Brooker S, Looman CW, Nagelkerke NJ, Habbema JD, Engels D: Quantification of clinical morbidity associated with schistosome infection in sub-Saharan Africa. Acta Trop 2003, 86:125-139

16. Conlon CP. Schistosomiasis. Medicine 2005, 33(8):64-67.

17. King CH, Dickman K, Tisch DJ: Reassessment of the cost of chronic helminthic infection: a meta analysis of disability-related outcomes in endemic schistosomiasis. Lancet 2005, 365:1520-1521.

18. Gryseels B, Polman K, Clerinx J, Kesterns L: Human schistosomiasis. Lancet 2006, 368:1106-1111

19. Barakat R, Farghaly A, El Masry AG, El-Sayed MK, Hussein MH: The epidemiology of schistosomiasis in Egypt: patterns of S. mansoni infection and morbidity in Kafr El-Sheikh. Am J Trop Med Hyg 2000, 62:21-27.

20. Boisier P, Serieye J, Ravaoalimalala VE, Roux J, Esterre P: Ultrasonographical assessment of morbidity in schistosomiasis mansoni in Madagascar: a community-based study in a rural population. Trans Roy Soc Trop Med Hyg 1995, 89:208-212.

21. Ouma JH, Fulford AJC, Kariuki HC, Kimani G, Sturrock RF, Muchemi G, Butterworth AE, Dunne DW: The development of Schistosomiasis mansoni in an immunologically naïve immigrant population in Masongaleni, Kenya. Parasitology 1998, 117:123-132.

22. Butterworth AE: Immunological aspects of human schistosomiasis. Br Bull 1998, 54:357-368.

23. Kabatereine NB, Kemijumbi J, Ouma JH, Sturrock RF, Butterworth $A E_{i}$ Madsen H, Ornbjerg N, Dunne DW, Vennervald BJ: Efficacy and side effects of praziquantel treatment in a highly endemic Schistosoma mansoni focus at Lake Albert, Uganda. Trans Roy Soc Trop Med Hyg 2003, 97:599-603.

24. Kabetereine NB, Vennervald BJ, Ouma JH, Kemijumbi J, Butterworth AE, Dunne DW, Fulford AJC: Adult resistance to schistosomiasis mansoni: age-dependence of re-infection remains in communities with diverse exposure patterns. Parasitol 1999, 118(01):101-105.

25. Fontanet AL, Woldemichael T, Sahlu T, van Dam GJ, Messele T, Rinke de Wit T, Masho W, Yeneneh H: Epidemiology of HIV and S. mansoni infections among sugar-estate residents in Ethiopia. Annals Trop Med Parasitol 2000, 94(2):145-155.

26. Borkow G, Bentwich Z: Chronic Immune Activation Associated with Chronic Helminthic and Human Immunodeficiency Virus Infections: Role of Hyporesponsiveness and Anergy. Clin Microb Rev 2004, 4:1012-1030.

27. Kallestrup P, Zinyama R, Gomo E, Butterworth AE, van Dam GJ, Erikstrup C, Ullum H: Schistosomiasis and HIV-1 infection in rural Zimbabwe: Implications for co-infection for excretion of Eggs. J Infect Dis 2005, 191:1311-1320.

28. Secor WE, Karanja DMS, Colley DG: Interactions between schistosomiasis and Human Immunodeficiency Virus in Western Kenya. Mem Inst Oswaldo Cruz Rio de Janeiro 2004, 99(Suppl 1):93-95.

29. Brown M, Mawa PA, Kaleebu P, Elliott AM: Helminths and HIV infection: epidemiological observation on immunological hypotheses. Parasites Imm 2006, 28:613-623.

30. Secor WE: Interactions between schistosomiasis and infection with HIV-1. Parasite Immunol 2006, 28:597-603.

31. Secor WE, Shah A, Mwinzi PMN, Ndenga BA, Watta CO, Karanja DMS Increased density of Human immunodeficiency virus Type 1 coreceptors CCR5 and CXCR4 on the surface of CD4 ${ }^{+}$T cells and monocytes of patients with Schistosoma mansoni infection. Infect Imm 2003, 71(11):6668-6671.

32. Nokta MA, Li XD, Nicholas J, Mallen M, Pou A, Asmuth D, Pollard RB: Chemokine/CD4 ${ }^{+}$receptor density ratios correlate with HIV replication in lymph node and peripheral blood of HIV-infected individuals. AIDS 2001, 15:161-169.

33. Kamal S, Bianchi L, AL Tawil A, Koziel M, El Sayed Khalifa K, Peter T, Rasenack $\mathrm{J}$ : Specific cellular immune response and cytokines patterns in patients co-infected with hepatitis C virus and Schistosoma mansoni. J Infect Dis 2001, 184:972

34. McElroy MD, Elrefaei M, Jones $N$, Ssali F, Mugyenyi $P$, Barugahare $B, C a o ~ H$ : Co-infection with Schistosoma mansoni is associated with decreased HIV-specific cytolysis and increased IL-10 production. The J I $\mathrm{mm} 2005$ 174:5119-5123.

35. Mellors JW, Rinaldo CR Jr, Gupta P, White RM, Todd JA, Kingsley LA: Prognosis in HIV-1 infection predicted by the quantity of virus in plasma. Science 1996, 272:1167-1170.

36. Brown M, Kizza M, Watera C, Quigley MA, Rowland S, Hughes P, Whitworth $J A G$, Ellioti AM: Helminth infection is not associated with faster progression of HIV disease in co-infected adults in Uganda. $J$ Infect Dis 2004, 190:1869-1879.

37. Elliot AM, Mawa PA, Joseph S, Namujju PB, Kizza M, Nakivingi JS, Watera C, Dunne DW, Whitworth JA: Associations between helminth infection and $\mathrm{CD}^{+} \mathrm{T}$ cell count, viral load and cytokines responses in HIV-1 infected Ugandan adults. Trans Roy Soc Trop Med Hyg 2003, 97:103-108.

38. Wolday D, Mayaan S, Mariam ZG, Berhe N, Seboxa T, Britton S, Galai N, Landay A, Bentwich Z: Treatment of intestinal worms is associated with decreased HIV plasma viral load. J Acq Imm Def Synd 2002, 32(1):56-62.

39. Modjarrad K, Zulu I, Redden DT, Njobvu L, Lane HC, Bentwich Z, Vermund $\mathrm{SH}$ : Treatment of intestinal helminths does not reduce plasma concentrations of HIV-1 RNA in co-infected Zambian adults. J Infects Dis 2005, 192(7):1277-1283.

40. Karanja DMS, Boyer AE, Strand M, Colley DG, Nahlen BL, Ouma JH, Secor EW: Studies on schistosomiasis in western Kenya: II. Efficacy of praziquantel for treatment of schistosomiasis in persons co-infected with human immunodeficiency virus-1. Am J Trop Med Hyg 1998, 59(2):307-311

41. Kallestrup P, Zinyama R, Gomo E, Butterworth AE, van Dam GJ, Gerstoft J, Erikstrup C, Ullum H: Schistosomiasis and HIV in rural Zimbabwe: Efficacy of treatment of schistosomiasis in individuals with HIV Co-infection. Clin Infects Dis 2006, 42:1781-1789.

42. Mwanakasale V, Vounatsou P, Sukwa TY, Ziba M, Ernest A, Tanner M: Interactions between Schistosoma haematobium and human immunodeficiency virus type 1: the effects of co-infection on treatment outcomes in rural Zambia. Am J Trop Med Hyg 2003, 69:420-428.

43. Mwinzi PNM, Karanja DMS, Kareko I, Magak PW, Orago ASS, Colley DG, Secor WE: Evaluation of hepatic fibrosis in persons co-infected with Schistosoma mansoni and Human Immunodeficiency Virus-1. Am J Trop Med Hyg 2004, 71(6):783-786.

44. Kjetland EF, Ndhlovu PD, Mduluza T, Gomo E, Gwanzura L, Mason PR, Kurewa EN, Midzi N, Friis H, Gundersen SG: Simple clinical manifestations 
of genital Schistosoma haematobium infection in rural Zimbabwean women. Am J Trop Med Hyg 2005, 72:311-319.

45. Downs JA, van Dam GJ, Changalucha JM, Corstjens PL, Peck RN, De Dood CJ, Bang H, Andreasen A, Kalluvya SE, van Lieshout L, Johnson WD Jr, Fitzgerald DW: Association of Schistosomiasis and HIV Infection in Tanzania. Am J Trop Med Hyg 2011, 4:84:3:364-369.

46. Mbabazi PS, Andan O, Fitzgerald DW, Chitsulo L, Engels D, Downs JA: Examining the relationship between urogenital schistosomiasis and HIV infection. PLOS Negl Trop Dis 2011, 5(12):e1396.

47. Sher AF, Coffman RL: Regulation of immunity to parasites and the hygiene hypothesis. Science 1992, 296:372-377.

48. Maizels RM, Bundy DAP, Selkrk ME, Smith DF, Anderson RM: Immunological modulation and evasion by helminth parasites in human populations. Nature 1993, 365:797-805.

49. Maizels RM, Yazdanbakh IM: Immune regulation by helminth parasites: cellular and molecular mechanisms. Nature Rev 2003, 3:733-744.

50. MacDonald AS, Araujo MI, Pearce EJ: Immunology of Parasitic helminth infections. Infect Immunol 2002, 70:427-433.

51. Stevenson M: HIV pathogenesis. Nature Med 2003, 9(7):853-860.

52. Lawn SD, Butera ST, Folks TM: Contribution of Immune Activation to the Pathogenesis and Transmission of Human Immunodeficiency Virus Type 1 Infection. Clin Microb Rev 2001, 14:753-777.

53. Clerici M, Shearer GM: A TH13TH2 switch is a critical step in the etiology of HIV infection. Immunol Today 1993, 14:107-111.

54. Romagnani S, Maggi E, Del Prete: HIV can induce a TH1 to TH0 shift, and preferentially replicates in CD4_T-cell clones producing TH2-type cytokines. Res Immunol 1994, 145:611-617.

55. Maggi E, Mazzetti M, Ravina A, Annunziato F, de Carli M, Piccinni MP Manetti R, Carbonari M, Pesce AM, Del Prete G: Ability of HIV to promote a $\mathrm{TH} 1$ to $\mathrm{TH} 0$ shift and to replicate preferentially in $\mathrm{TH} 2$ and $\mathrm{TH} 0$ cells. Science 1994, 265:244-248.

56. Cossarizza A, Ortolani C, Mussini C, Borghi V, Guaraldi G, Mongiardo N, Bellesia E, Franceschini MG, De Rienzo B, Franceschi C: Massive activation of immune cells with an intact $T$ cell repertoire in acute human immunodeficiency virus syndrome. J Infect Dis 1995, 172:105-112.

57. Graziosi C, Gantt KR, Vaccarezza M, Demarest JF, Daucher M, Saag MS, Shaw GM, Quinn TC, Cohen OJ, Welbon CC, Pantaleo G, Fauci AS: Kinetics of cytokine expression during primary human immunodeficiency virus type 1 infection. Proc Natl Acad Sci USA 1996, 93:4386-4391.

58. Rizzardi GP, Barcellini W, Tambussi G, Lillo F, Malnati, Perrin L, Lazzarin A: Plasma levels of soluble CD30, tumour necrosis factor (TNF)-alpha and TNF receptors during primary HIV-1 infection: correlation with HIV-1 RNA and the clinical outcome. AIDS 1996, 10:F45-F50.

59. Sinicco A, Biglino A, Sciandra M, Forno B, Pollono AM, Raiteri R, Gioannini P: Cytokine network and acute primary HIV-1 infection. AIDS 1993, 7:1167-1172.

60. Groux H, Bigler M, de Vries JE: Interleukin-10 induces a long-term antigenspecific anergic state in human CD4 ${ }^{+}$T cells. J Exp Med 1996, 184:19-29.

61. Tanchot C, Guillaume S, Delon J: Modifications of CD8+ T cell function during in vivo memory or tolerance induction. $/ \mathrm{mm}$ 1998, 8:581-590.

62. Scotto L, Naiyer AJ, Galluzzo S: Overlap between molecular markers expressed by naturally occurring $\mathrm{CD} 4^{+} \mathrm{CD} 25^{+}$regulatory $\mathrm{T}$ cells and antigen specific $\mathrm{CD} 4^{+} \mathrm{CD} 25^{+}$and $\mathrm{CD} 8+\mathrm{CD} 28+\mathrm{T}$ suppressor cells. Hum Immunol 2004, 65:1297-1306.

63. Elrefaei M, Ventura FL, Baker CA: HIV-specific IL-10- positive CD8 ${ }^{+} \mathrm{T}$ cells suppress cytolysis and IL-2 production by CD8+ T cells. J Immunol 2007, 178:3265-3271.

64. Cosmi L, Liotta F, Lazzeri E: Human $C D 8^{+} \mathrm{CD} 25^{+}$thymocytes share phenotypic and functional features with $\mathrm{CD} 4^{+} \mathrm{CD} 25^{+}$regulatory thymocytes. Blood 2003, 102:4107-4114.

65. Elferafaei M, Burke CM, Baker CAR, Jones NG, Bousheri S, Bangsberg DR, Cao H: HIV-Specific TGF-b-Positive CD4 ${ }^{+} \mathrm{T}$ Cells Do Not Express Regulatory Surface Markers and Are Regulated by CTLA-4. AIDS Res Hum Retroviruses 2010, 26(3):329-337.

66. Gorelik L, Flavell RA: Transforming growth factor-beta in T-cell biology. Nat Rev Immunol 2002, 2:46-53.

67. Riley JL, Schlienger K, Blair PJ: Modulation of susceptibility to HIV-1 infection by the cytotoxic T lymphocyte antigen 4 costimulatory molecule. J Exp Med 2000, 191:1987-1997.

68. Cheever AW, Yap GS: Immunologic basis of disease and disease regulation. Chemical Immun 1997, 66:159-176.
69. Cheever AW, Hoffmann KF, Wynn TA: Immunopathology of schistosomiasis mansoni in mice and men. Immunol Today 2000, 21:465-466.

70. Montenegro SM, Miranda P, Mahanty S, Abath FG, Teixeira KM, Coutinho EM, Brinkman J, Goncalves I, Domingues LA, Domingues AL, Sher A, Wynn TA: Cytokines production in acute versus chronic human schistomiasis mansoni: the cross-regulatory role of interferon- $\gamma$ and interleukin-10 in the responses of peripheral blood mononuclear cells and splenocytes to parasites antigens. J Infect Dis 1999, 179:1502-1514.

71. McSorley HJ, Maizels RM: Helminth infections and host immune regulation. Clin Microb Rev 2012, 25(4):585-608.

72. de Jesus AR, Silva A, Santana LB, Magalhaes A, de Jesus AA, de Almeida RP, Rego MA, Burattini MN, Pearce EJ, Carvalho EM: Clinical and immunologic evaluation of 31 patients with acute schistosomiasis mansoni. $J$ Infect Dis 2002, 185:98-105

73. Caldas IR, Campi-Azevedo AC, Oliveira LF, Silveira AM, Oliveira RC, Gazzinelli G: Human schistosomiasis mansoni: immune responses during acute and chronic phases of the infection. Acta Trop 2008, 108:109-117.

74. Dunne DW, Pearce EJ: Immunology of hepatosplenic schistosomiasis mansoni: a human perspective. Micr Infect 1999, 1:553-560.

75. Buchan RD, Fine DP, Colley DG: Schistosoma mansoni infection in mice of thymus-dependent lymphocytes. I. Pathology and altered pathogenesis. Am J Path 1973, 71:207-218.

76. Doenhoff MJ: A role for granulomatous formation in the transmission of infectious disease: schistosomiasis and tuberculosis. Parasitology 1997, 115:S113-S125.

77. Fallon PG, Dunne DW: Tolerization of Mice to Schistosoma mansoni Egg Antigens Causes Elevated Type 1 and Diminished Type 2 Cytokine Responses and Increased Mortality in Acute Infection. J Immun 1999, 162(7):4122-4132.

78. Mwinzi PNM, Karanja DMS, Colley DG, Orago ASS, Secor WE: Cellular Immune responses of schistosomiasis patients are altered by Human Immunodefiency Virus Type 1 co-infection. J Infect Dis 2001, 184:488-496.

79. Malenganisho WLM: The role of HIV, micronutrient status and treatment in Schistosoma mansoni infection and morbidity: a cohort study among adult of Ukerewe and Mwanza districts, Tanzania.: PhD thesis, Faculty of Science, University of Copenhagen and DBL- Institute for Health Research and Development; 2005

80. N'Zoukoudi-N'Doundou MY, Dirat I, Akouala JJ, Penchenier L, Makuwa M, Rey JL: Bilharziasis and human immunodeficiency virus infection in Congo. Med Trop (Mars) 1995, 55:249-251.

81. Actor JK, Shirai M, Kullberg MC, Buller RM, Sher A, Berzofsky JA: Helminth infection results in decreased virus-specific CD8 ${ }^{+}$cytotoxic T-cell and $\mathrm{Th}_{1}$ cytokines response as well as delayed virus clearance. Proc Natl Acad Sci USA 1993, 90:948-952.

82. Karanja DMS, Colley DO, Nahlen Bl, Ouma JH, Evan Secor W: Studies on schistosomiasis in western Kenya: I. Evidence for immune-facilitated excretion of schistosome eggs from patients with Schistosoma mansoni and Human Immunodeficiency virus co-infections. Am J Trop Med Hyg 1997, 11:5:56:5:515-521.

83. Mkhize-Kwitshana ZL, Taylor M, Jooste P, Mabaso MLH, Walzi G: The influence of different helminth infection phenotypes on immune response against HIV in co-infected adults in South Africa. BMC Infect Dis 2011, 11:273.

84. van Dam GJ, Wichers JH, Ferreira TMF, Ghati D, van Amerongen A, Deelder AM: Diagnosis of schistosomiasis by reagent strip test for detection of circulating cathodic antigen. J Clin Microbiol 2004, 42:5458-5461.

85. Maggi E, Mazzetti M, Ravina A, Annunziato F, De Carli M, Pierre Piccinni M, Manetti R, Carbonari M, Maria Pesce A, Del Prete G, Romagnani S: Ability of HIV to promote a $\mathrm{Th}_{1}$ to $\mathrm{Th}_{0}$ shift and to replicate preferentially in $\mathrm{Th}_{2}$ and $\mathrm{Th}_{0}$ cells. Science 1994, 265:244-248.

86. Everts $\mathrm{B}$, Perona-Wright $\mathrm{G}$, Smits $\mathrm{HH}$, Hokke $\mathrm{CH}$, van der Ham AJ, Fitzsimmons CM, Doenhoff MJ, van der Bosch J, Mohrs K, Haas H, Mohrs M, Yazdanbakhsh M, Schramm G: Omega-1, a glycoprotein secreted by Schistosoma mansoni eggs, drives $\mathrm{Th}_{2}$ responses. J Exp Med 2009, 206(8):1673-1680

87. Abdulla MH, Lim KC, McKerrow JH, Caffrey CR: Proteomic identification of IPSE/alpha-1 as a major hepatotoxin secreted by Schistosoma mansoni eggs. PLoS Negl Trop Dis 2011, 5(10):e1368.

88. Fitzsimmons CM, Schramm G, Jones FM, Chalmers IW, Hoffmann KF, Grevelding CG, Wuhrer M, Hokke CH, Haas H, Doenhoff MJ, Dunne DW: 
Molecular characterization of omega-1: A hepatotoxic ribonuclease from Schistosoma mansoni eggs. Mol Biochemical Parasitol 2005, 144:123-127.

89. Doenhoff MJ, Hassounah O, Murare H, Bain J, Lucas S: The schistosome egg granuloma: immunopathology in the cause of host protection or parasite survival? Trans Roy Soc Med Hyg 1986, 80:503-514

90. Dunne DW, Jones FM, Doenhoff MJ: The purification, characterization, serological activity and hepatotoxic properties of two cationic glycoproteins $\left(a_{1}\right.$ and $\left.\omega_{1}\right)$ from Schistosoma mansoni eggs. Parasitology 1991, 103(02):225-236.

91. Pearce EJ, MacDonald AS: The immunobiology of schistosomiasis. Nat Rev Immunol 2002, 2:499-511.

92. Ayash-Rashkovsky M, Chenine AL, Steele LN, Lee SJ, Song R, Ong H, Rasmussen RA, Hofmann-Lehmann R, Else JG, Augostini P, McClure HM, Secor WE, Ruprech $\mathrm{RM}$ : Co-infection with Schistosoma mansoni reactivates viremia in Rhesus Macaques with chronic Simian-Human Immunodefiency virus Clade C infection. Infect Imm 2007, 75(4):1751-1756.

93. Moreno-Fernandez ME, Presicce $P$, Chougnet CA: Homeostasis and Function of Regulatory T cells in HIV/SIV Infection. J Virol 2012, 86:10262-10269.

94. Watanabe K, Mwinzi PNM, Black CL, Muok EMO, Karanja DMS, Secor WE, Colley DG: T-regulatory cell levels decrease in people infected with Schistosoma mansoni on effective treatment. Am J Trop Med Hyg 2007, 77:676-682.

95. Seddiki N, Santner-Nana B, Martinson J, Zaunders J, Sasson S, Landay A, Solomon M, Selby W, Alexander SI, Nanan R, Kelleher A, Fazekas de St. Groth B: Expression of interleukin (IL)-2 and IL-7 receptors discriminates between human regulatory and activated T cells. J Exp Med 2006, 203:1693-1700.

96. Liu W, Putnam AL, Xu-yu Z, Szot GL, Lee MR, Zhu S, Gottlieb AP, Kapranov P, Gingeras TR, Fazekas de St. Groth B, Clayberger C, Soper DM, Ziegler SF, Bluestone JA: CD127 expression inversely correlates with FoxP3 and suppressive function of human CD4 ${ }^{+}$T reg cells. J Exp Med 2006, 203:1701-1711

97. World Health Organization: Prevention and control of schistosomiasis and soil transmitted helminthiasis. Geneva: World Health Organization; 2002. WHO Technical Report Series, No 912

98. Ferrari MLA, Coelho PMZ, Antunes CMF, Tavares CAP, da Cunha AS: Efficacy of oxamniquine and praziquantel in the treatment of Schistosoma mansoni infection: a controlled trial. Bull WHO 2003, 81(3):190-196.

99. Sabah AA, Fletcher C, Webbe G, Doenhoff MJ: Schistosoma mansoni: reduced efficacy of chemotherapy in infected T-cell deprived mice. Exp Parasitol 1985, 60:348-354.

100. Modha J, Lambertucci JR, Doenhoff MJ, McLaren DJ: Immune dependence of schistosomicidal chemotherapy: an ultrastuctural study of Schistosoma mansoni adult worms exposed to praziquantel and immune serum in vivo. Parasites $1 \mathrm{~mm}$ 1990, 12:321-334

101. Doenhoff MJ: The immune-dependence of chemotherapy in experimental schistosomiasis. Memorial Inst Oswaldo Cruzi Rio de Janeiro 1989, 84(Suppl 1):31-37.

102. Chinine AL, Buckley KA, Li PL, Rasmussen RA, Ong H, Jiang S, Wang T, Augostini P, Secor WE, Ruprecht RM: Schistosoma mansoni infection promotes SHIV clade C replication in rhesus macaques. AIDS 2005, 19:1793-1797.

103. Walson J, John-Stewart G: Treatment of helminth co-infection in HIV-1 infected individuals in resource-limited settings. Cochrane Database Syst Rev 2008, 1:CD006419.

104. Walson JD, John-Stewart G: Treatment of helminth co-infection in individuals with HIV-1: A systematic review of literature. PLoS Negl Trop Dis 2007, 1(3):e102.

105. Modjarrad K, Vermund SH: Effect of treating co-infections in HIV-1 viral load. Lancet Infect Dis 2010, 10:455-463.

106. Sangare $L R$, Herrin $B R$, John-Stewart G, Walson JD: Species-specific treatment effects of helminth/HIV-1 co-infection: A systematic review and meta-analysis. Parasitol 2011, 138:1546-1558.

107. Grogan JL, Kremsner PG, Deelder AM, Yazdanbakhsh M: Elevated proliferation and interleukin- 4 release from $\mathrm{CD}^{+}$cells after chemotherapy in human Schistosoma haematobium infection. Eur J Immunol 1996, 26:1365-1370.

108. Wolday D, Mayaan S, Mariam ZG, Berhe N, Seboxa T, Britton S, Galai N, Landay A, Bentwich Z: Treatment of Intestinal worms is Associated with decreased HIV plasma viral load. J Acq Imm Def Synd 2002, 31(1):56-62.

109. Kallestrup P, Zinyama R, Gomo E, Butterworth AE, Mudenge B, van Dam GJ, Gerstoft J, Erikstrup C, Ullum H: Schistosomiasis and HIV-1 infection in rural Zimbabwe: Effect of treatment of schistosomiasis on CD4+ cell count and plasma HIV-1 RNA load. J Infect Dis 2005, 192:1956-1961.
110. Lawn SD, Karanja DMS, Mwinzi P, Andove J, Colley DG, Folks TM, Secor WE: The effect of treatment of schistosomiasis on blood plasma HIV-1 RNA concentration in co-infected individuals. AIDS 2000, 14:2437-2443.

111. Brown M, Mawa PA, Joseph S, Bukusuba J, Watera C, Whitworth JAG, Dunne DW, Elliott AM: Treatment of Schistosoma mansoni infection increases helminth-specific type 2 cytokine responses and HIV-1 loads in coinfected Ugandan adults. J Infect Dis 2005, 191:1648-1657.

112. Kamal SM, Khalifa ES: Immune modulation by helminthic infections: worms and viral infections. Parasites Immun 2006, 28:483-496.

113. Joseph S, Jones FM, Walter K, Fulford AJ, Kimani G, Mwatha JK, Kamu T, Kariuki HC, Kazibwe F, Tukahebwa E, Kabatereine NB, Ouma JH, Vennervald BJ, Dunne DW: Increases in human Thelper 2 cytokines responses to Schistosoma mansoni worm and worm tegument antigens are specifically induced by treatment with praziquantel. J Infect Dis 2004, 190:835-842.

114. Vennervald BJ, Kenty L, Butterworth $\mathrm{AE}$, Kariuki $\mathrm{CH}$, Kadzo H, Ireri E, Amaganga C, Kimani G, Mwatha J, Otedo A, Booth M, Ouma JH, Dunne DW: Detailed clinical and ultrasound examination of children and adolescents in a Schistosoma mansoni endemic areas in Kenya: hepatosplenic disease in the absence of portal fibrosis. Trop Med Intern Health 2004, 9(4):461-470.

115. Cheever AW, Andrade ZA: Pathological lesions associated with Schistosoma mansoni infection in man. Trans R Soc Trop Med Hyg 1967 61:626-639.

116. Mosimann JE, Malley JD, Cheever AW, Clark CB: Size and shape analysis of schitosome eggs-counts in Egyptian autopsy data. Biometrics 1978, 34:341-356.

117. Hatz CFR: The use of ultrasound in schistosomiasis. Adv Parasitol 2001, 48:225-284.

118. Jenkins JM, Hatz C, The Cairo Working Group: The use of diagnostic ultrasound in schistosomiasis-attempts at standardization of methodology. Acta Trop 1992, 51:45-63.

119. Richter J, Hatz C, Campane G, Jenkins J: Ultrasound in schistosomiasis. A practical guide to the standardized use of ultrasonography for the assessment of schistosomiasis morbidity. Geneva: World Health Organization; TDR/STR/ $\mathrm{SCH} / 00.1$.

120. King CH, Magak P, Salam EA, Ouma JH, Kariuki HC, Blanton RE: Measuring morbidity in schistosomiasis mansoni: relationship between image pattern, portal vein diameter and portal branch thickness in large-scale surveys using new WHO coding guidelines for ultrasound in schistosomiasis. Trop Med Intern Health 2003, 8(2):109-117.

121. Yazdanpanah Y, Thomas A, Kardorff R, Talla I, Sow S, Niag M, Stelma FF, Decam C, Rogerie F, Gryseels B, Capron A, Doehring E: Organometric investigation of the spleen and liver by ultrasound in Schistosoma mansoni endemic and non endemic villages in Senegal. Am J Trop Med Hyg 1997, 57:245-249.

122. de Jesus AR, Miranda DG, Miranda RG, Arau'jo I, Magalha'es A, Bacelar M, Carvalho EM: Morbidity associated with Schistosoma mansoni infection determined by ultrasound in an endemic area of Brazil, Caatinga do Moura. Am J Trop MedHyg 2000, 63;1(2):1-4.

123. Kabatereine NB: Schistosoma mansoni in a fishing community on the shores of Lake Albert at Butiaba, Uganda: epidemiology, morbidity, re-infection patterns and impact of treatment with praziquantel. PhD thesis. Denmark: University of Copenhagen.

124. Gerns HL, Sangaré LR, Walson JL: Integration of Deworming into HIV Care and Treatment: A Neglected Opportunity. PLoS Negl Trop Dis 2012, 6(7):e1738.

125. Secorevan W: The effects of schistosomiasis on HIV/AIDS infection, progression and transmission. Curr Opin HIV AIDS 2012, 7:254-259.

126. Doenhoff MJ, Bain J: The immune-dependence of schistosomicidal chemotherapy: relative lack of efficacy of an antimonial in Schistosomainfected mice deprived of their T-cells and the demonstration of drug-antiserum synergy. Clin Exp Imm 1978, 33:232-238.

127. Brindley PJ, Strand M, Norden AP, Sher A: Role of host antibody in the chemotherapeutic action of praziquantel against Schistosoma mansoni: identification of target antigens. Mol Biochem Parasitol 1989, 34:99-108.

doi:10.1186/2049-9957-2-2

Cite this article as: Mazigo et al.: Epidemiology and interactions of Human Immunodeficiency Virus - 1 and Schistosoma mansoni in subSaharan Africa. Infectious Diseases of poverty 2013 2:2. 